9 Weingarten K. Tics (Chap. 30). In: Vinken PJ, Bruyn GW, eds. Handbook of Clinical Neurology, Vol. 6. Amsterdam: NorthHolland Publishing Co. 1968;796.

${ }^{10}$ Bonduelle M. The myoclonias (Chap. 29). In: Vinken PJ, Bruyn GW, eds. Handbook of Clinical Neurology, Vol. 6. Amsterdam: North-Holland Publishing Co., 1968;770.

"Owens DGC, Johnstone EC. Spontaneous involuntary disorders of movement. Arch Gen Psych 1982;39:460.

${ }^{12}$ Gowers WR. Epilepsy and Other Chronic Convulsive Diseases: Their Causes Symptoms and Treatment. New York: Dover Publications Inc., 1964;37, 46-7.

${ }^{13}$ Penfield W, Jasper H. Epilepsy and Functional Anatomy of the Human Brain Boston: Little Brown \& Co., 1941;396.

${ }^{14}$ Cushing $\mathrm{H}$. A note upon the faradic stimulation of the post-central gyrus in conscious patients. Brain 1909;32:44-53.

Accepted 14 October 1983

\section{Epileptic pain: a temporal lobe focus}

Sir: Pain as a manifestation of epilepsy is most unusual. When described it has often been associated with a structural lesion in the parietal lobe.' We recently encountered a 30-year-old man who had suffered paroxysms of left facial pain for eleven years; a diagnosis of trigeminal neuralgia had been made and he had been treated accordingly with anticonvulsants. $\mathrm{He}$ responded to treatment with carbamazepine and phenytoin. The true nature of his pain was established when he was admitted for elective posterior fossa exploration and microvascular decompression of the trigeminal nerve. ${ }^{2}$

In July 1982 a 30-year-old man was admitted for microvascular decompression of the left trigeminal nerve. His symptoms had begun eleven years prior to this and a diagnosis of trigeminal neuralgia had been made. He responded to treatment with carbamazepine and phenytoin. The pain always came on during early sleep and would waken him. The pain was sharp, usually confined to the left cheek but occasionally radiating behind the left ear. The duration of each paroxysm was variable and could last for fifteen seconds, and was occasionally associated with twitching of either the left side of the face or the left leg. He also admitted to frequent brief episodes of unpleasant taste, although he denied any episodes of déjà vu, jamais vu, olfactory hallucinations or episodes of loss of consciousness. As both carbamazepine and phenytoin had been commenced simultaneously, it was uncertain whether two anti-convulsants were required to control the symptoms. The phenytoin was reduced; this was followed by increasingly frequent attacks of nocturnal left facial pain which on most occasions were followed by a typical tonic-clonic seizure. The EEG showed repetitive focal sharp and slow wave discharges in the right mid-temporal region. During one recording he fell asleep and experienced a typical episode of his left facial pain which was followed by a brief tonic-clonic seizure. Phenytoin was reintroduced with the subsequent control of symptoms. A CT scan performed both with and without contrast was normal.

In 1901 Gowers $^{3}$ in his review of three thousand cases of epilepsy wrote "sensations referred to the head preceded fits in 90 cases ... local pain may stimulate neuralgia". Thus in his experience epilepsy was associated with pain in $1 \%$ of patients. Russell $^{4}$ reviewed 266 patients with focal epilepsy and found pain as the aura in only six $(2 \cdot 2 \%)$ whilst in a further case pain was preceded by a focal motor seizure. Details of the site of pain and underlying pathology were not discussed in his article. In the majority of patients with epileptic pain there is a structural abnormality. Of 20 patients (including the present case) in the literature, only two suffered from idiopathic epilepsy. In a further two the cause of epilepsy was not stated whilst tumour (eight), stroke (five), trauma (two) and cysticercosis (one) caused epilepsy in the remainder. ${ }^{\text {s-10 }}$

Penfield" on the basis of cortical stimulation experiments stated "the fact that only 11 times out of well over 800 responses did the patient use the word pain to describe a cortical sensation, probably indicates that pain had little if any cortical representation". Ten years later, however, Penfield together with Kristiansen ${ }^{12}$ reported two patients who described pain as the initial sensory phenomena. Both patients had their lesion in the precentral gyrus and electrical stimulation at this site reproduced the aura. Wilkinson' however felt that epileptic pain was of localising value indicating a lesion in the parietal lobe. Where enough details were provided a parietal lobe abnormality was present in 12 of the cases. In two the proposed site of the origin of the pain was not stated whilst in a further four the epilepsy occurred in patients who had suffered a hemiplegia and the EEG had revealed a mid-hemisphere focus $^{5}$ on each occasion. In York's patient without a structural abnormality the EEG revealed ictal activity in the right central region. The present case however showed a right mid-temporal focus. Although trigeminal neuralgia and tonic-clonic seizures have been described in association with multiple sclerosis, ${ }^{13}$ the absence of any other evidence after eleven years makes this diagnosis unlikely. This is the firs instance, to our knowledge, in which epileptic pain has been associated with a focal EEG abnormality in the temporal lobe and thus pain associated with epilepsy is not necessarily a localising feature of parietal lobe lesions.

The characteristics of epileptic pain as described in 20 cases are that it may be either localised to the contralateral face or limbs rarely to the genitals ${ }^{9}$ or it may be diffuse.' The pain may begin in one area but subsequently spread to other parts of the body as the electrical activity spreads across the cortex. ${ }^{\circ 7}$ Epileptic pain is typically brief, lasting only seconds but may persist for some minutes, and it is almost invariably associated with either focal or generalised seizures; however it is possible that patients suffering from epileptic pain may not have been recognised in the absence of more obvious evidence of seizure activity. In those cases where treatment was discussed epileptic pain responded wett to anti-convulsant therapy.

We thank the staff of the EEG Departmen of the Newcastle General Hospital for the invaluable assistance.

$$
\begin{array}{r}
\text { P GATES } \\
\text { T NAYERNOUR⿳一由八冂卄 } \\
\text { RP SENGUPT } \\
\text { Regional Neurological Centre, } \\
\text { Newcastle General Hospital, } \\
\text { Westgate Road, } \\
\text { Newcastle Upon Tyne NE4 6BE, } \\
\text { United Kingdom }
\end{array}
$$

\section{References}

' Wilkinson HA. Epileptic pain. An uncommon manifestation with localising value. Neurol ogy (Minneap) 1973;23:518-20.

2 Gardner WJ, Miklos MV. Response of trigeminal neuralgia to decompression of sensory root. Discussion of cause of trigemina neuralgia. JAMA 1959;170:1773-6.

${ }^{3}$ Gowers WR. Epilepsy and Other Chronic Convulsive Diseases. Their Causes, Symptom and Treatment. 2nd ed. London: JA Churchill, 1901.

4 Russell WR. Brain Memory and Learning. London: Oxford University Press, 1959, 85-87.

s Fine $W$. Post-hemiplegic epilepsy in the $N$ elderly. Br Med J 1967;1:199-200.

- Head H, Holmes G. Sensory disturbances from cerebral lesions. Brain 1911;34: 102-254. 
' Lewin W, Phillips CG. Observations on partial removal of the post-central gyrus for pain. $J$ Neurol. Neurosurg and Psychiatry 1952;15:143-7.

${ }^{8}$ Penfield W, Erickson TC. Epilepsy and cerebral localisation, treatment and prevention of epileptic seizures. London: Bailliere, Tindall and Cox, 1941, 99.

9 York GK, Gabor AJ, Dreyfus PM. Paroxysmal genital pain: An unusual manifestation of epilepsy. Neurology (Minneap) 1979; 29:516-9.

${ }^{10}$ Michelsen JJ. Subjective disturbances of the sense of pain from lesions of the cortex. Res Publ Assoc Ner Ment Dis 1943;25:86-99.

"Penfield W, Boldrey B. Somatic motor and sensory representation in the cerebral cortex of man as studied by electrical stimulation. Brain 1937;60:389-443.

${ }_{12}$ Penfield W, Kristiansen K. Epileptic seizure patterns. A study of the localising value of initial phenomena in focal cortical seizures. Springfield, Illinois: CC Thomas, 1951, 37, $39,81$.

${ }^{13}$ McAlpine D, Lumsden CE, Acheson ED. Multiple Sclerosis: A Reappraisal. Edinburgh and London: ES Livingstone Ltd, 1965.

Neuralgic amyotrophy after administration of tetanus toxoid

Sir: I report a case of neuralgic shoulder amyotrophy. This condition has been described after passive immunisation against tetanus with horse-serum, and was formerly referred to as "serum neuritis". There are very few cases in the literature ${ }^{1-4}$ mentioning this condition after active immunisation with tetanus toxoid. The onset usually follows booster-immunisation. The syndrome consists of severe neuralgia followed by the onset of paresis in the related muscles of the shoulder girdle. The pattern of paresis is peripheral, not radicular, and the prognosis is generally considered to be fair. Diagnosis is usually dependent on the natural course ${ }^{5}$ because there are no specific findings to enable the physician to come to an early diagnosis.

A twenty-year-old soldier, who had just joined the Army, was routinely administered two tetanus toxoid vaccinations at a four-week interval. Two weeks after the administration of the "booster-shot" he noticed the sudden onset of severe leftsided neuralgia spreading to the left shoulder muscles and into the left biceps. At the same time slight right-sided shoulder neuralgia was noticed. Four days after the onset of the neuralgic syndrome almost total paresis of the left deltoid muscle occurred. The soldier was referred to a military hospital, where a cervical CT scan suggested a left-sided cervical disc protru- sion extending into the left intervertebral foramen at the level $\mathrm{C} 5 / \mathrm{C} 6$. This was thought to be consistent with a diagnosis of a left-sided $\mathrm{C} 6$ root compression syndrome and the patient was referred to our neurosurgical unit to undergo a cervical Cloward procedure. On admission the patient presented with a complete paresis on the left deltoid muscle, a severe weakness of the left triceps, and moderate weakness of the left pronator teres. The left triceps reflex was absent with all other refiexes being normal. No sensory deficit could be found and thorough neurological examination revealed no other abnormalities. Electromyographic studies showed denervation of the affected muscles the sensory pathways not being affected. We repeated the cervical CT scan and performed a cervical myelogram with consecutive CT, ${ }^{6}$ both of which were normal. During the first week as an inpatient the neuralgia gradually ceased. As all laboratory findings (CSF, immune electrophoresis) were normal, we made the diagnosis of neuralgic shoulder amyotrophy after tetanus toxoid administration.

The few cases in the literature describing the condition of neuralgic shoulder amyotrophy after tetanus toxoid seem to share a similar pattern. The patients were usually young, healthy subjects, all of whom had been vaccinated against tetanus several times before. ' It was always the "boostershot" that led to the onset of the neuralgic amyotrophy.

\section{JÜRGEN CW KIWIT Abt.XII/Neurochirurgie, Bundeswehrzentralkrankenhaus, Rübenacher Straße 170, 5400 Koblenz, West Germany}

\section{References}

${ }^{1}$ Wooling KR, Rushton JG. Serum neuritis: report of two cases and brief review of the syndrome. Arch Neurol Psych 1950;64:56873.

2 Johnson EW. Peripheral neuropathy and tetanus-toxoid. JAMA; 1966;198:1030-1.

${ }^{3}$ Gersbach $P$, Waridel D. Paralysie après prévention antitétanique. Schweiz Med Wschr 1976;106:150-3

${ }^{4}$ Baust W, Meyer D, Wachsmuth W. Peripheral neuropathy after administration of tetanus toxoid. J Neurol 1979;222:131-3.

${ }^{5}$ Gathier JC, Bruyn GW. Vaccinogenic peripheral neuropathies. In: Handbook of Clinical Neurology, Vinken PJ, Bruyn GW eds. New York: Elsevier 1970, Vol. 8, 86-94.

${ }^{6}$ Sabiers HHK, Kiwit JCW. Frühe Diagnostik zervikaler Wurzelausrisse. Wehrmedizinische Monatsschrift 1983;27:234-48.
7 Quast U, Hennessen W, Widmark RM. Monoand polyneuritis after tetunus vaccination (1970-1977). International Symposium on Immunization: Benefit versus risk factors, Brussels 1978. Develop Bio! Standard 1979; 43:25-32.

${ }^{8}$ Hopf HCh. Guillain-Barré-Syndrome nach Tetanus-Schutz-Impfung. Akt Neurol 1980; 7:195-200.

Accepted 8 October 1983

Painful hyperaesthesia following resection of the lateral cutaneous nerve of the thigh

Sir: A patient is described in whom hyperaesthesia followed resection of a peripheral nerve. Functional reorganisation of the dorsal horn neurons seemed to be the best explanation for this phenomenon.

In 1980 the patient, a 25-year-old married woman, fell down in the street, fractured the processus transversus of the fourth lumbar vertebra, and developed a haemato$\mathrm{ma}$ in the left thigh. The present illness began in May 1981 with burning pain and paraesthesiae in the left thigh. In July 1981 ه neurologist found that she had a hyperaes $\omega$ thetic painful area which covered the regio $\overrightarrow{0} \vec{\omega}$ innervated by the lateral femoral cutaneou+ nerve. Clinical examination and electro myography revealed that the lesion was situated at the peripheral level. There was no denervation activity in the muscles innervated by roots L2-4. On the left side the sensory evoked potential was not large enough to be measured. The diagnosis of meralgia paraesthetica was made, with an assumption that it was due to trauma.

Since conservative therapy with mild analgesics and physical therapy proved unsuccessful an orthopedic surgeon was consulted in October 1981; he resected a 20 $\mathrm{cm}$ long piece of the affected nerve. After the operation the hyperaesthetic region was much smaller, but within a few weeks the hyperaesthetic area began to grow until it was of the original size. It was suspected that there were still some nerve branches left. Therefore, local anaesthetic was injected at the inguinal level; after this injection the size of the hyperaesthetic region decreased about $50 \%$, confirming the suspicion. The patient was referred for re-exploration. The orthopedic surgeon found that just distally to the inguinal ligament the nerve divided into two branches. The medial branch had been resected in the first operation and there were no connections from the resected nerve stump which could explain the regrowth of the hyperaesthetic area. An 